\title{
Development and Implementation of a Reversible Variable Speed Heat Pump Model for Model Predictive Control Strategies
}

\author{
Riccardo Toffanin ${ }^{1,2}$, Thibault Péan ${ }^{1,2}$, Joana Ortiz ${ }^{1,2}$, Jaume Salom ${ }^{1}$ \\ ${ }^{1}$ Catalonia Institute for Energy Research (IREC), Sant Adrià de Besòs (Barcelona), Spain \\ ${ }^{2}$ Universitat Politècnica de Catalunya (UPC), Barcelona, Spain
}

\begin{abstract}
Flexibility in the energy demand of buildings equipped with Heat Pumps (HPs) may be a solution for the congestion and instability problems of the electrical energy system. However, this flexibility potential is difficult to quantify due to the lack of Variable Speed Heat Pump (VSHP) models in building simulation programs. The purpose of the present work is to present the development of an air-to-water reversible VSHP model in TRNSYS and its application in an energy flexibility scenario of Economic Model Predictive Control (EMPC) in a residential building. A simple but effective combination of TRNSYS Types is used to reproduce the behaviour of a VSHP, while its part load performance is modelled from manufacturer data. When compared with a fixed capacity HP, results showed that in the thermostatic control of the developed model both energy and monetary savings are achievable. These positive effects are even higher when the operation of the HP is managed by the EMPC, reaching a reduction of cost of $50 \%$ while maintaining the comfort of the occupants.
\end{abstract}

\section{Introduction}

Buildings are responsible for $40 \%$ of the total European energy consumption, and $75 \%$ of the European building stock is considered as energy inefficient (European Commission, 2016). The European Union (EU) has established an objective of a $30 \%$ improvement in energy efficiency by 2030 in order to ameliorate the situation. This policy has supported the electrification of heating and cooling systems, with the number of installed Heat Pumps (HPs) increasing by a factor of four from 2006 to 2015 (European Commission, 2016; European Heat Pump Association (EHPA), 2018). This increase in electricity consumption could cause problems of congestion and instability in the electric grid (Jensen et al., 2017). These issues could be, in turn, amplified by the integration of more fluctuating renewable energy sources, like solar and wind, into the EU energy mix (Jensen et al., 2017).

A transition from generation on demand to consumption on demand might be part of the solution to solve these issues. Different loads can provide flexibility but concentrating on buildings will be fundamental because of their high share in the total consumption. The most common building typology is residential (European Commission, 2018), and, for this reason, it is one of the most interesting category for an energy flexibility analysis.

Building energy demand, especially the thermal load, is partially controllable (Le Dréau \& Heiselberg, 2016). Depending on the particular construction, the demand for Domestic Hot Water (DHW), Space Heating (SH), Space Cooling (SC), and ventilation, and/or the consumption of electrical appliances used by the occupants can be adjusted or shifted to a certain extent without impacting thermal comfort (Jensen et al., 2017). The introduction of flexibility is made possible, especially for the heating and cooling demand, by storage technologies that are available in the building, such as the embedded thermal mass of the construction, DHW tanks, phase change materials storage systems, or batteries (Jensen et al., 2017).

Flexibility in building energy consumption can be achieved by introducing control strategies on the building system. They can mainly be divided into Rule-Based Control (RBC) and Model Predictive Control (MPC). RBC consists of simple strategies based on the introduction of specific rules, for example change in room temperature set-point, when a trigger signal, e.g. the electricity price, reaches a pre-determined limit (Péan, Salom, \& Costa-Castelló, 2018b). MPC strategies are based on the prediction of the future performance of the building using simplified models and on the optimization of the operating strategy over a receding horizon. The chosen objective is usually the minimization of system cost. MPC strategies are often more complex to develop and implement, but generally yields more effective results (Péan et al., 2018b).

Consequently, energy flexibility in buildings will become of utmost importance in the coming years, and for all the above-mentioned reasons, it is fundamental to examine and estimate the energy flexibility potential of residential buildings, especially those equipped with heat pumps.

The easiest and cheapest way to investigate this topic is with computer simulations. However, building simulation software, such as TRNSYS (which is used in this paper), mostly model Fixed Capacity Heat Pumps (FCHPs), even if Variable Speed Heat Pumps (VSHPs) are already widely available in the market. This limits the energy performance and flexibility analysis because a FCHP is characterized by an on-off behaviour, necessary to match the building thermal demand at lower/part load. Such operation creates inefficiencies due to the parasitic losses 
related to cycling and undermines the overall performance by increasing the total electricity consumption (Fuentes, et al., 2017). On the other hand, VSHPs are capable of modulating the frequency of the compressor and, thus, changing the delivered capacity according to the needs of the building. This type of device avoids the consecutive on-off cycle and, thus, has a better performance thanks to its ability to work at part load where the efficiency of an air-to-water heat pump is higher (Fahlén, 2012). For this reason, the lack of VSHP models in TRNSYS is an important limitation to the analysis and estimation of the energy performance of building, because such HPs are already present in the market reality.

In this context, the present work aims at presenting the development of a reversible air-to-water VSHP model based on manufacturer data. This model is applied in an MPC strategy for the activation of the flexibility of the building thermal demand. Firstly, the available FCHP model in TRNSYS is described. Secondly, the VSHP performance modelling is presented, followed by the VSHP model implementation in TRNSYS. Then, the MPC strategy is described and the key performance indicators are presented. Finally, the energy flexibility MPC strategy is applied with the VSHP, in a TRNSYSMATLAB co-simulation platform, where the HP operation is optimized using as input the variable electricity price. This framework enables to reveal the potential savings of such controls when compared to the conventional thermostat operation of the building in summer and in winter. A total of three scenarios per season are presented: a base case with a FCHP in the building, and two scenarios where the dwelling is equipped with a VSHP, one with fixed supply temperature and another with supply temperature managed by the Economic MPC (EMPC).

\section{Heat Pump}

The reversible air-to-water heat pump chosen for this study is a model from the Yutaki series of HITACHI. Data regarding the performance of the heat pump are available in the manufacturer catalogue (Hitachi Air Conditioning Products Europe, 2016). The rated parameters are 4.30 $\mathrm{kW}$ of heating capacity with a COP of 3.00 (outdoor temperature of $7^{\circ} \mathrm{C}$, water inlet and outlet temperature of $40{ }^{\circ} \mathrm{C}$ and $45{ }^{\circ} \mathrm{C}$, respectively) and $1.64 \mathrm{~kW}$ of cooling capacity with a COP of 3.80 (outdoor air temperature of $35^{\circ} \mathrm{C}$, water inlet and outlet temperature of $12{ }^{\circ} \mathrm{C}$ and 7 ${ }^{\circ} \mathrm{C}$, respectively).

\section{FCHP Implementation in TRNSYS}

An air-to-water FCHP is usually modelled in TRNSYS with Type 941, which calculates the full load performance based on user-supplied data at different water inlet and ambient conditions.

It is controlled with a two-level control system. The DHW aquastat or zone temperature thermostat represent the first level control that activates the HP when there is need of $\mathrm{DHW}, \mathrm{SH}$, or SC. In order to control the HP supply water a second control is necessary, with fixed set-points of $60^{\circ} \mathrm{C}$ for $\mathrm{DHW}$ and of $40^{\circ} \mathrm{C}$ for $\mathrm{SH}$, and of $15^{\circ} \mathrm{C}$ for $\mathrm{SC}$. Hence, when the first level control is on, the HP is switching on and off to maintain the supply temperature on average at the desired temperature.

The degradation of the efficiency due to the on-off behaviour, necessary to respect the desired set-points (on the zone temperature and on the water supply temperature) is taken into account with a Part Load Factor (PLF) coefficient. The PLF is defined as the ratio between the Coefficient Of Performance (COP) at part load $C O P_{P L}$ and the steady state COP at equivalent full load operating conditions $C O P_{F L}$. It adapts the COP due to the frequent start-up and/or long stand-by periods at part load (Fuentes et al., 2017). The Part Load Ratio (PLR) identifies at which part load the HP is working and it is the ratio between building thermal demand and HP capacity at full load.

The actual value of the COP is obtained using the equation given in Fuentes et al. (2017) and reproduced in (1) which is similar to the correlation presented in the standard EN14825 for air-to-water heat pumps (European Committee for Standardization (CEN), 2013), but it is more detailed since it considers not only stand-by losses but also start-up losses:

$$
P L F=\left(1+\frac{C_{d}(1-P L R)}{1-C_{d}(1-P L R)}+\left(1-C_{c}\right) \frac{1-P L R}{P L R}\right)^{-1}
$$

where $C_{d}$ is the degradation coefficient due to start-up losses, and $C_{c}$ is the degradation coefficient of the heat pump due to stand-by losses. $C_{d}$ is equal to 0.2 while $C_{c}$ is equal to 0.9 according to EN14825 and manufacturer catalogue. This relation is only valid for the FCHP, and, thus, the PLF is always lower or equal to 1 in this case.

\section{VSHP Performance Modelling}

From the manufacturer data alone, it was not possible to create a complete part load performance map since the part load performance data given were not sufficient. Only 10 part load data points were available compared to 84 data points at full load. A linear interpolation is therefore assumed between the available data to estimate the performance at different operating conditions.

The PLF-PLR curve is obtained by interpolating both the available and the estimated part load data using a quadratic fit $\left(\mathrm{R}^{2}=0.92\right)$ (see (2)). For PLR values falling below the minimum percentage of continuous modulation, the VSHP reverts to an on-off behaviour, and (1) is adapted (see (3)). The PLF-PLR curve is presented in Figure 1 (top) along with a scatter of the part load data points. The observed data confirm the typical increase of COP at part load for VSHP (Fahlén, 2012). The decay of the COP below PLR $=0.25$ shows that the HP shifts to on-off operation, consistent with the information obtained from the manufacturer.

The PLF-PLR relation for $P L R \geq 0.25$ is:

$$
P L F=1.646 \times P L R^{2}-3.588 \times P L R+2.932
$$

while for $P L R<0.25$ is:

$$
P L F=2.3\left(1+\frac{C_{d}\left(1-\frac{P L R}{0.25}\right)}{1-C_{d}\left(1-\frac{P L R}{0.25}\right)}+\left(1-C_{c}\right) \frac{1-\frac{P L R}{0.25}}{\frac{P L R}{0.25}}\right)^{-1}
$$

It is assumed that the PLF-PLR curve is valid also for cooling mode due to the lack of part load data for cooling 


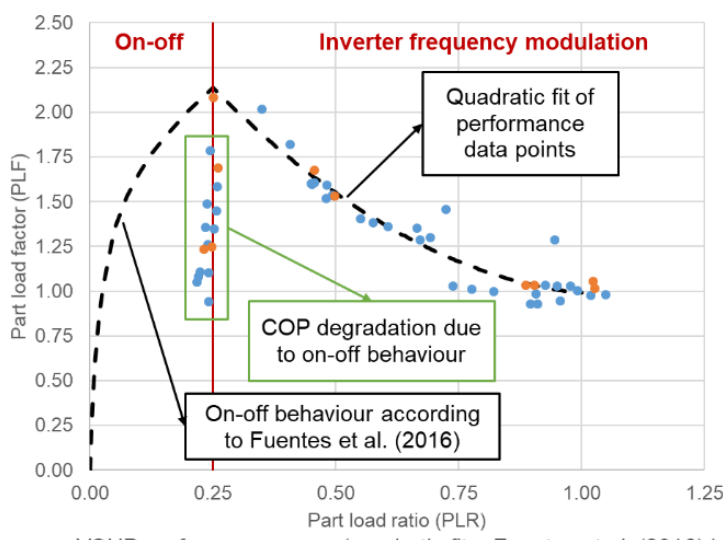

- - VSHP performance curve (quadratic fit + Fuentes et al. (2016) - Operation mode limit

- Estimated Data

- Manufacturer Data

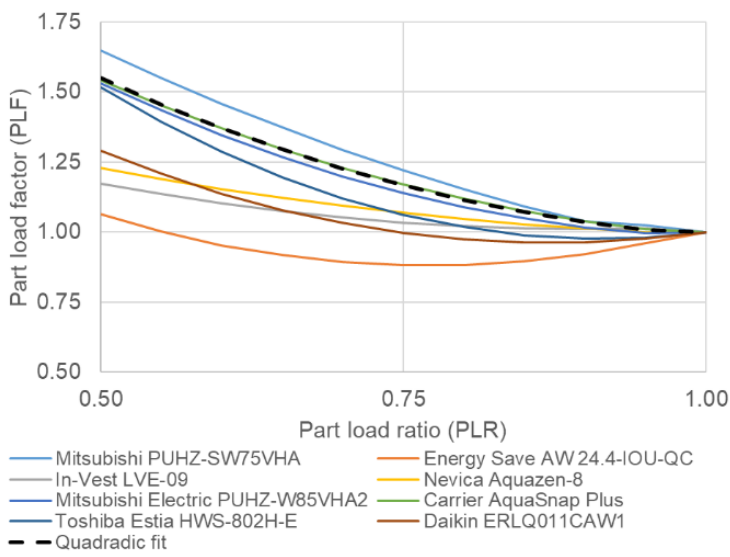

Figure 1: Part load performance of the VSHP (top) and comparison with literature (bottom)

operation. Schibuola et al. (2015) developed the part load curve of a VSHP for both heating and cooling operation. The average absolute difference of the PLF between the two curves at a same PLR was less than 0.09, therefore the previous hypothesis is considered reasonable.

The assumed part load curve significantly influences the final results; therefore, some precautions must be taken. The hypothetical relation derived from manufacturer data may be different from the real part load curve of the heat pump. Nevertheless, a similar approach of part load performance estimation was found in (Filliard, Guiavarch, \& Peuportier, 2009). Furthermore, the performance curves of 8 air-to-water VSHP retrieved from the database of the Swedish Energy Agency were compared with the estimated performance curve of the chosen VSHP (Swedish Energy Agency, 2018). The analysed heat pumps have a similar quadratic trend for the PLF at part load, as can be seen in Figure 1 (bottom), and therefore, the estimated curve was considered to be reliable. In addition, Burba (2013) and Horikawa et al. (2018) presented a part load curve of an air-conditioning system that reached values of PLF around 2.0 at low PLR, similar to the current study.

\section{VSHP Implementation in TRNSYS}

The VSHP model is a combination of the Type 941 for an air-to-water FCHP with other TRNSYS Types and additional equations. It was modelled by combining Type 941 and Type 43 which uses the part load curve to calculate the coefficient of performance at part load $C O P_{P L}$. Type 23, a Proportional Integral Differential (PID) controller connected to the supply water temperature of the heat pump, is also added. This controller works when there is demand for $\mathrm{SH}$ or SC with a water set-point of $40^{\circ} \mathrm{C}$ and $15^{\circ} \mathrm{C}$, respectively, and of $62.5^{\circ} \mathrm{C}$ for DHW. The output control signal, representing the part load ratio of the heat pump, is limited between 0.25 and 1.00 , with the lower limit being the minimum part load operation of the heat pump from the manufacturer specifications. Additional equations are also included in order to recalculate the outputs of the heat pump at part load.

Figure 2 shows the flowchart with the part load calculation methodology. The steps followed at each iteration until reaching the convergence of the TRNSYS calculations are as follows:

1. the outdoor air temperature $T_{A I R}$ in ${ }^{\circ} \mathrm{C}$ and the inlet temperature of the water $T_{W A T E R-I N}$ in ${ }^{\circ} \mathrm{C}$ are sent as inputs to Type 941, which then calculates the full load capacity $Q_{F L}$ in $\mathrm{kJ} / \mathrm{h}$ and the full load coefficient of performance $C O P_{F L}$ at these current operating conditions based on full load manufacturer data, similarly than the FCHP;

2. Type 23 calculates the PID control signal, equivalent to the PLR, that satisfies the building thermal demand;

3. the full load capacity $Q_{F L}$ from Type 941 and the PID

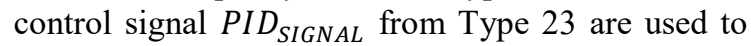
calculate the part load capacity in $\mathrm{kJ} / \mathrm{h}$ :

$$
Q_{P L}=Q_{F L} \times P I D_{S I G N A L}
$$

4. $Q_{P L}, Q_{F L}$, and $C O P_{F L}$ are sent to Type 43 that calculates the power input at part load $P_{P L}$ in $\mathrm{kJ} / \mathrm{h}$ and the coefficient of performance $C O P_{P L}$, using the part load performance curve;

5. the outlet water temperature of the HP $T_{W A T E R-O U T}$ is then calculated with:

$$
T_{W A T E R-O U T}=T_{W A T E R-I N}+\frac{Q_{P L} \times(1-2 S C)}{4.19 \times \dot{m}_{W A T E R}}
$$

where $\dot{m}_{W A T E R}$ is the mass flow rate of water in $\mathrm{kg} / \mathrm{h}$ (fixed to a constant value when the HP is on) and $S C$ is the SC operation flag.

In the previous equations (4) and (5), the thermal power, $Q_{P L}$ or $Q_{F L}$, is always positive (thermal cooling power for $\mathrm{SC}$ and thermal heating power for $\mathrm{SH}$ and $\mathrm{DHW}$ ).

However, the model does not perfectly imitate the real operation of a VSHP which changes the frequency of the compressor to modulate the thermal output and meet the thermal demand of the building. This behaviour was not possible to be reproduced because the frequency control system of the heat pump is internal, and it is seen only as a black box. Nonetheless, the used approach reproduces the final effect of the frequency regulation, which is the capability of the heat pump to work at part load. 


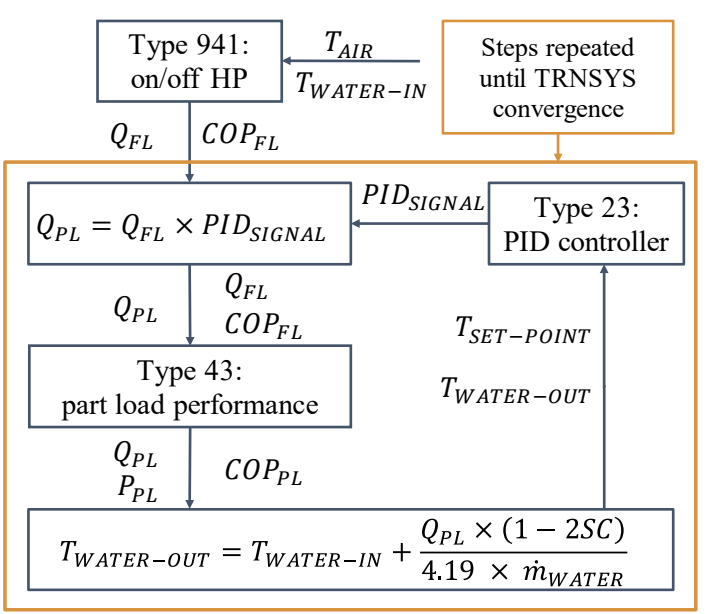

Figure 2: Flow chart of part load performance calculation methodology

\section{Case Study}

The residential building chosen as case study is a dwelling located in Terrassa $\left(41.570^{\circ} \mathrm{N}, 2.013^{\circ} \mathrm{E}\right)$, close to Barcelona, Spain, and, therefore in the Mediterranean region. The building is representative of a multi-storey building typology of the period from 1991 to 2007 which is built under the Catalan building regulation NRE-AT87. The building is modelled in TRNSYS, and was previously presented and validated in (Ortiz, 2016). Its main characteristics are summarized in Table 1.

Table 1: Main characteristics of the building

\begin{tabular}{|c|c|}
\hline Parameter & Value \\
\hline Floor area & $108.5 \mathrm{~m}^{2}$ \\
\hline Window area & $19.6 \mathrm{~m}^{2}$ \\
\hline $\begin{array}{l}U \text {-value of the } \\
\text { walls }\end{array}$ & $0.6 \mathrm{~W} / \mathrm{m}^{2} \mathrm{~K}$ \\
\hline $\begin{array}{c}U \text {-value of the } \\
\text { windows }\end{array}$ & 2.5 to $5.7 \mathrm{~W} / \mathrm{m}^{2} \mathrm{~K}$ \\
\hline $\begin{array}{l}g \text {-value of the } \\
\text { windows }\end{array}$ & 0.5 to $0.76 \mathrm{~W} / \mathrm{m}^{2} \mathrm{~K}$ \\
\hline Infiltration $n_{50}$ & $3 \mathrm{~h}^{-1}$ \\
\hline $\begin{array}{c}\text { Hot and cold } \\
\text { water production }\end{array}$ & Reversible air-to-water HP \\
\hline $\begin{array}{l}\text { SH and SC } \\
\text { emitter }\end{array}$ & 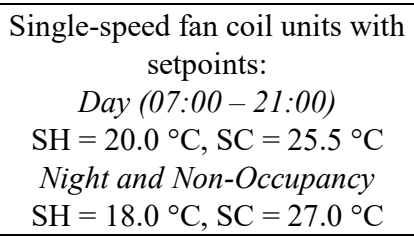 \\
\hline DHW storage & 250 litres tank (fully-mixed) \\
\hline
\end{tabular}

\section{MPC Strategy}

MPC uses a reduced model of the building to forecast its future behaviour. For this purpose, the building envelope is modelled as a second-order RC (resistance-capacity) grey-box model as represented in Figure 3. Reynders et al. (2014) already proved that two-state models are sufficient for the scope of an energy flexibility analysis.

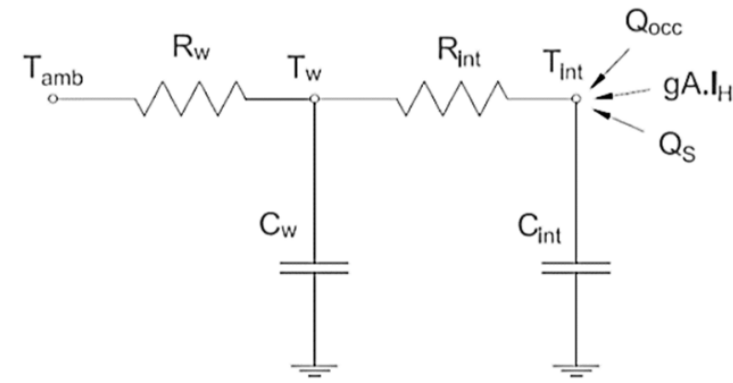

Outputs

$T_{\text {int }}=$ average indoor operative temperature

$T_{w}=$ average internal surface temperature

Inputs

$Q_{s}=$ HP delivered thermal power

$T_{a m b}=$ outdoor air temperature

$I_{H}=$ ground horizontal solar irradiation

$Q_{\text {OCC }}=$ heat gain within the envelope

Estimated parameters

$C_{\text {int }}$ and $C_{w}=$ thermal capacities of the two states

$R_{\text {int }}$ and $R_{w}=$ thermal resitances of the two states

$g A=$ aperture area of the windows

Figure 3: Schematic of the second order RC grey-box model

Datasets created using the more detailed TRNSYS model are used to estimate the parameters of this simplified model. The datasets were generated with a PseudoRandom Binary Signal (PRBS), a binary sequence that is used to excite the building at different frequencies, by controlling the space heating and cooling operation of the HP (Bacher \& Madsen, 2011). More details on the reduced model used in this study, its formulation as a state-space model, and the estimation of the parameters are available in (Péan, Salom, \& Costa-Castelló, 2018a). The simplified model used in this paper has a fit of $91.12 \%$

\section{Optimal Control Problem Formulation}

MPC is based on the resolution of an Optimal Control Problem (OCP) in order to optimize the performance of the system according to the chosen objective. The OCP used in this study is described as follows:

$$
\min _{u_{C}, \delta} J=\alpha_{O B J} \times J_{\Delta u}+\left(1-\alpha_{O B J}\right) \times J_{C O S T}
$$

where $J_{\Delta u}$ and $J_{C O S T}$ are the objective terms, and $\alpha_{O B J}$ is their weighting coefficient. For every time-step $k$ within the prediction horizon $N \forall k \in \llbracket 1, N \rrbracket$, the model is:

$$
\left\{\begin{array}{c}
\boldsymbol{x}(k+1)=\boldsymbol{A} \boldsymbol{x}(k)+\boldsymbol{B}_{\boldsymbol{C}} \boldsymbol{u}_{\boldsymbol{C}}(k)+\boldsymbol{B}_{\boldsymbol{x}} \boldsymbol{u}_{\boldsymbol{x}}(k) \\
\boldsymbol{y}(k+1)=\boldsymbol{C} \boldsymbol{x}(k)
\end{array}\right.
$$

where $\boldsymbol{x}$ is the temperature states vector, $\boldsymbol{y}$ is the system outputs vector, $\boldsymbol{u}_{\boldsymbol{C}}$ is the vector of the controlled inputs (thermal powers), $\boldsymbol{u}_{\boldsymbol{X}}$ is the vector of the uncontrolled inputs (weather and occupancy), whereas $\boldsymbol{A}, \boldsymbol{B}_{\boldsymbol{C}}, \boldsymbol{B}_{\boldsymbol{X}}$, and $\boldsymbol{C}$ are the state space matrices containing the model parameters.

The constraints (see Table 2) for the inputs are:

$$
\begin{gathered}
\delta_{S}(k) \times \underline{Q_{H P}} \leq Q_{S}(k) \leq \delta_{S}(k) \times \overline{Q_{H P}} \\
\delta_{T E S}(k) \times \underline{Q_{H P}} \leq Q_{T E S}(k) \leq \delta_{T E S}(k) \times \overline{Q_{H P}}
\end{gathered}
$$




$$
\delta_{S}(k)+\delta_{T E S}(k) \leq 1
$$

where $\delta_{S}$ and $\delta_{T E S}$ are $\mathrm{SC} / \mathrm{SH}$ and Thermal Energy Storage (TES) on/off variables, $Q_{S}$ and $Q_{T E S}$ are HP thermal delivered power for $\mathrm{SH} / \mathrm{SC}$ and for $\mathrm{DHW}$ respectively, and $\underline{Q_{H P}}$ and $\overline{Q_{H P}}$ are the lower and upper boundary of HP thermal delivered power.

The constraints (see Table 2) for the outputs are:

$$
\begin{aligned}
& \underline{T_{I N T}} \leq T_{I N T}(k) \leq \overline{T_{I N T}} \\
& \underline{T_{T E S}} \leq T_{T E S}(k) \leq \overline{T_{T E S}}
\end{aligned}
$$

where $T_{I N T}$ is the average indoor temperature, $T_{I N T}$ and $\overline{T_{I N T}}$ are its lower and upper boundaries, whereas $T_{T E S}$ is the TES water temperature, and $\underline{T_{T E S}}$ and $\overline{T_{T E S}}$ are its lower and upper boundaries.

Table 2: Constraints of the model parameters

\begin{tabular}{|c|c|}
\hline \multicolumn{2}{|c|}{ Constraints } \\
\hline \multirow{3}{*}{$Q_{H P}$} & {$[1.075 \mathrm{~kW} ; 4.300 \mathrm{~kW}]$ for SH } \\
& {$[-1.640 \mathrm{~kW} ;-0.410 \mathrm{~kW}]$ for SC } \\
& {$[1.075 \mathrm{~kW} ; 4.300 \mathrm{~kW}]$ for DHW } \\
\hline \multirow{3}{*}{$T_{I N T}$} & {$\left[20.0^{\circ} \mathrm{C} ; 23.8^{\circ} \mathrm{C}\right]$ in winter days } \\
& {$\left[18.0^{\circ} \mathrm{C} ; 22.7^{\circ} \mathrm{C}\right]$ in winter nights or unoccupancy } \\
& {$\left[23.0^{\circ} \mathrm{C} ; 26.4^{\circ} \mathrm{C}\right]$ in summer days } \\
& {$\left[24.8^{\circ} \mathrm{C} ; 27.6^{\circ} \mathrm{C}\right]$ in summer nights or unoccupancy } \\
\hline$T_{T E S}$ & {$\left[50^{\circ} \mathrm{C} ; 65^{\circ} \mathrm{C}\right]$} \\
\hline
\end{tabular}

The term $J_{\text {COST }}$ is the minimization objective of the MPC strategy, the electricity cost, and is defined as:

$$
\begin{aligned}
& J_{C O S T}=\sum_{k=1}^{N} p_{E L}(k) \frac{\left\|u_{C}(k)\right\|}{\operatorname{COP}(k)} \\
& J_{C O S T}=\sum_{k=1}^{N} p_{E L}(k) \frac{Q_{S}+Q_{T E S}}{\operatorname{COP}(k)} \\
& J_{C O S T}=\sum_{k=1}^{N} p_{E L}(k) P_{H P}(k)
\end{aligned}
$$

where $p_{E L}$ is the electricity price and $P_{H P}$ is the electrical consumption of the HP. It is a linear term because the COP of the HP is simplified with a linear relation depending on the outdoor air and the HP supply temperature, considered as a fixed value that changes with the operation mode (Siegenthaler, 2016; Verhelst, 2012). The term $J_{\Delta u}$ is the smoothing term of the HP operation, and is defined as:

$$
J_{\Delta u}=\sum_{k=2}^{N}\left\|u_{C}(k)-u_{C}(k-1)\right\|
$$

It is introduced in the objective function in order to penalize power peaks and switches of operating mode (Verhelst, 2012).

In order to find the accurate value for the coefficient $\alpha_{O B J}$, Pareto fronts were developed for heating and cooling simulations. The values of $\alpha_{O B J}$ were selected considering a trade-off between the required computational time to solve the MPC algorithm and the weight between the major objective and the smoothing term. The weighing coefficient $\alpha_{O B J}$ changes seasonally ( 0.2 for summer and 0.1 for winter).

\section{Co-simulation Platform}

A TRNSYS-MATLAB co-simulation platform is used in order to implement the MPC strategy explained in the previous sections. The detailed building model in TRNSYS gives the possibility to assess the control strategy without having to implement it in a real building. MATLAB and Yalmip (Lofberg, 2004) are the tools used to formulate the mixed integer linear programming OCP. The OCP is solved using the Gurobi solver (Gurobi Optimization LLC., 2018) with a discretization time step $t_{s}$ of $12 \mathrm{~min}$ and a time prediction horizon $N$ of 120 time steps. The prediction horizon corresponds to 24 hours, allowing to reproduce the daily patterns observed in occupancy, weather, and electricity price.

For the co-simulation, Type 155 of TRNSYS calls MATLAB every simulation hour and then MATLAB runs the MPC controller, determining the optimal operation for the prediction horizon, the next 24 hours. Only the first control actions (HP thermal powers and on-off signals) are then sent back to TRNSYS, enabling a more detailed simulation of the dynamic behaviour with the more accurate model using a higher time resolution ( 3 minutes time steps).

\section{Key Performance Indicators}

In this section the selected performance indicators for energy and flexibility and for thermal comfort are presented.

\section{Energy and Flexibility}

The thermal demand of the building in $\mathrm{kWh}$ is defined as:

$$
Q_{H P}=\int_{0}^{t_{T O T}}\left(Q_{S}+Q_{T E S}\right) d t
$$

where $t_{T O T}$ represents the total simulation time. The electricity consumption of the heat pump in $\mathrm{kWh}$ is defined as:

$$
E_{H P}=\int_{0}^{t} t_{T O T} P_{H P}(t) d t
$$

The electricity cost is calculated using the Voluntary Price for the Small Consumer (PVPC, in its Spanish acronym) available on the website of the Red Eléctrica de España (Red Eléctrica de España, 2017). The two-period hourly price with a high daily variation was used due to its better applicability for flexibility purposes. The HP operation cost in EUR is calculated with the following equation:

$$
C_{E L}=\int_{0}^{t_{T O T}} p_{E L}(t) P_{H P}(t) d t
$$

The Flexibility Factor (FF) is defined as (Le Dréau \& Heiselberg, 2016):

$$
F F=\frac{\int_{L P T} P_{H P}(t) d t-\int_{H P T} P_{H P}(t) d t}{\int_{L P T} P_{H P}(t) d t+\int_{H P T} P_{H P}(t) d t}
$$

where the two integrals represent the electricity consumption in kWh during Low Price Time (LPT) and High Price Time (HPT), respectively, defined using the $30^{\text {th }}$ and $70^{\text {th }}$ percentiles as thresholds. The FF represents the amount of electricity consumed during high-price hours or low-price hours, and it can be interpreted as a load shifting indicator. The value range is between -1 and 1 , with $\mathrm{FF}=-1$ indicating that there is no consumption during low-price hours, while $\mathrm{FF}=1$ means that no electricity is consumed when the price is high. 


\section{Thermal Comfort}

To evaluate the comfort conditions, the Long-term Percentage of Dissatisfied (LPD) was chosen because it is a general long-term indicator. It is normalised over the calculation period, the analysed zones of the building and the number of occupants. Thermal comfort is achieved when the LPD is lower than 20\% (Ortiz, 2016). It is a function of a short-term index; in this case the PPD (predicted percentage of dissatisfied) defined by Fanger is used. The LPD is defined as:

$$
L P D=\frac{\sum_{j=1}^{T} \sum_{z=1}^{Z}\left(p_{z, j} P P D_{z, j} t_{j}\right)}{\sum_{j=1}^{T} \sum_{z=1}^{Z}\left(p_{z, j} t_{j}\right)}
$$

where $j$ is the counter of TRNSYS simulation time step, $z$ is the counter of the building zone, $Z$ is the total number of zones analysed in the building, $p_{z, j}$ is the number of occupants of zone $z$ at time $k, t_{j}$ is the duration of the time step of the TRNSYS simulation.

\section{Results and Discussion}

Three different scenarios per season were analysed in this study: a first scenario named FCHP, where the building model is equipped with the FCHP, a second scenario called VSHP, where the building model has a VSHP controlled by a PID controller, and a third scenario where the building is equipped with the VSHP whose operation is managed by the EMPC strategy (Scenario EMPC).

The interpretation of the results did not contemplate the impact of the model uncertainties, notably of the building model (fit of 91.12\%) and the VSHP performance curve $\left(\mathrm{R}^{2}\right.$ of $92 \%$ ). These uncertainties can have a certain impact on the results, and it would be worth but complex to evaluate how they propagate from the models to the final results through the overall co-simulation framework with the MPC controller. The savings reported here just represent the best-case upper bounds. However, it was shown in (Maasoumy et al., 2014) that with a model uncertainty below $30 \%$ (like the current case study), a MPC controller provides greater savings compared to rule-based control, and thus these upper bounds do not represent such an unrealistic goal. Furthermore, it is important to emphasize that closed-loop feedback, which is provided by the MPC repeated optimization process, helps the MPC to offset model uncertainties and external disturbances (Halvgaard, 2014).

The simulations are conducted for a winter and a summer season using weather data of 2015. The chosen simulation periods are the week of January from 18-01 to 25-01 and the week of July from 08-07 to 15-07. Table 3 and Table 4 present the results of the simulations conducted in winter and summer, respectively. The percentage in brackets represents the variation of the variable in comparison with Scenario FCHP, which is the base case.

As can be seen from Table 3 and Table 4, in winter the electricity consumption decreases from $103.57 \mathrm{kWh}$ in Scenario FCHP to $86.80 \mathrm{kWh}(-16.19 \%)$ in Scenario VSHP and to $75.14 \mathrm{kWh}(-27.45 \%)$ in Scenario EMPC, whereas in summer it decreases from $39.31 \mathrm{kWh}$ in Scenario FCHP to $36.86 \mathrm{kWh}(-6.23 \%)$ in Scenario VSHP and to $22.07 \mathrm{kWh}(-43.85 \%)$ in Scenario EMPC. This result is a consequence of the ability of a VSHP to work at part load, where the COP of an air-to-water VSHP increases. The reduction is higher for Scenario EMPC because the control system also considers the efficiency of the heat pump. Hence, it is aware of the periods when the HP efficiency is higher, for example when the outdoor temperature is higher in heating operation, and it tends to operate the VSHP during these hours. Thus, the EMPC more successfully optimizes the HP consumption.

This reduction of electricity consumption in the cases with VSHP cause, in turn, a decrease in the electricity cost. The cost is reduced by $18.01 \%$ in winter and by $3.11 \%$ in summer for Scenario VSHP. Moreover, in Scenario EMPC the percentage of cost reduction is higher than the percentage of the electricity reduction, so the savings are not only due to the decrease in consumption, but also to the load shifting. Consequently, the electricity consumption is reduced by $50.18 \%$ in winter and $51.39 \%$ in summer for Scenario EMPC. It is important to bear in mind that if the VSHP had a different part load curve, the PLF-PLR relation might not have been as favourable at low PLR, and in such case the savings could be less significant. In fact, in the analysed literature savings were comprised between 15\% and 40\% (Péan et al., 2018b).

Table 3: Results of winter simulations

\begin{tabular}{|c|c|c|c|}
\hline Scenario & FCHP & VSHP & EMPC \\
\hline $\begin{array}{c}\text { SH Demand } \\
{[\mathrm{kWh}]}\end{array}$ & 216.95 & $\begin{array}{c}214.08 \\
(-1.32 \%)\end{array}$ & $\begin{array}{c}260.08 \\
(+19.88 \%)\end{array}$ \\
\hline $\begin{array}{c}\text { DHW Demand } \\
{[\mathrm{kWh}]}\end{array}$ & 57.12 & $\begin{array}{c}57.15 \\
(+0.05 \%)\end{array}$ & $\begin{array}{c}58.10 \\
(+1.70 \%)\end{array}$ \\
\hline $\begin{array}{c}\text { Electricity } \\
\text { Consumption } \\
{[\mathrm{kWh}]}\end{array}$ & 103.57 & $\begin{array}{c}86.80 \\
(-16.19 \%)\end{array}$ & $\begin{array}{c}75.14 \\
(-27.45 \%)\end{array}$ \\
\hline $\begin{array}{c}\text { Electricity Cost } \\
{[\text { [EUR] }}\end{array}$ & 11.75 & $\begin{array}{c}9.64 \\
(-18.01 \%)\end{array}$ & $\begin{array}{c}5.86 \\
(-50.18 \%)\end{array}$ \\
\hline FF & -0.48 & $\begin{array}{c}-0.52 \\
(-0.04)\end{array}$ & $\begin{array}{c}0.64 \\
(+1.12)\end{array}$ \\
\hline-[
\end{tabular}

Table 4: Results of summer simulations

\begin{tabular}{|c|c|c|c|}
\hline Scenario & FCHP & VSHP & EMPC \\
\hline $\begin{array}{c}\text { SC Demand } \\
{[\mathrm{kWh}]}\end{array}$ & 118.94 & $\begin{array}{c}118.65 \\
(-0.24 \%)\end{array}$ & $\begin{array}{c}102.82 \\
(-13.56 \%)\end{array}$ \\
\hline $\begin{array}{c}\text { DHW Demand } \\
{[\mathrm{kWh}]}\end{array}$ & 49.78 & $\begin{array}{c}49.71 \\
(-0.13 \%)\end{array}$ & $\begin{array}{c}49.87 \\
(+0.19 \%)\end{array}$ \\
\hline $\begin{array}{c}\text { Electricity } \\
\text { Consumption } \\
{[\mathrm{kWh}]}\end{array}$ & 39.31 & $\begin{array}{c}36.86 \\
(-6.23 \%)\end{array}$ & $\begin{array}{c}22.07 \\
(-43.85 \%)\end{array}$ \\
\hline $\begin{array}{c}\text { Electricity Cost } \\
{[\text { EUR] }}\end{array}$ & 5.07 & $\begin{array}{c}4.91 \\
(-3.11 \%)\end{array}$ & $\begin{array}{c}2.46 \\
(-51.39 \%)\end{array}$ \\
\hline $\begin{array}{c}\text { FF } \\
{[-]}\end{array}$ & -0.76 & $\begin{array}{c}-0.84 \\
(-0.11)\end{array}$ & $\begin{array}{c}-0.13 \\
(+0.63)\end{array}$ \\
\hline
\end{tabular}

As expected, the EMPC strategy achieves the highest monetary savings due to its ability to shift the consumption of the HP towards low-price hours. In fact, the FF passes from -0.48 and -0.76 in the base case in winter and summer, respectively, to 0.64 and -0.13 in Scenario EMPC. 
The shift of the electricity consumption can also be appreciated in Figure 4 that show the electricity consumption of the heat pump over the two days of the simulation period in winter (top) and summer (bottom). Moreover, the FF of Scenario VSHP is worse than Scenario FCHP in both seasons. A possible explanation for this is that the VSHP works for a longer time, albeit at lower power consumption, than the FCHP, and so the prolonged operation occurs mostly at higher price periods.

Regarding the thermal demand of the building, Scenario FCHP and Scenario VSHP have similar demands in terms of magnitude since their control system is thermally-driven. However, as Figure 4 shows, the trend is different since the HP is usually activated at the same time, but it avoids the on-off cycle (the blue parts in Figure 4) in Scenario VSHP. On the other hand, Scenario EMPC changes completely the demand pattern, operating the heat pump during the night when the price for electricity is low. Due to this load shift, the optimization that controls the HP operation changes the delivered thermal energy. It is higher for $\mathrm{SH}(+19.88 \%)$ and for DHW $(+1.70 \%)$ in winter, but lower for SC $(-13.56 \%)$ and almost equal for DHW $(+0.19 \%)$ in summer. The difference in winter may be since the HP works more during the night in EMPC when the outdoor temperature is lower (that also means lower HP efficiency), therefore it needs to deliver more thermal energy due to higher losses to the outside. On the other hand, the lower SC demand in summer may be explained by the fact that the EMPC system is able to use the HP at an even lower PLR than Scenario VSHP; thus, it can satisfy the demand delivering less energy. Moreover, this can also be due to the load shifting towards night time. The price signal is
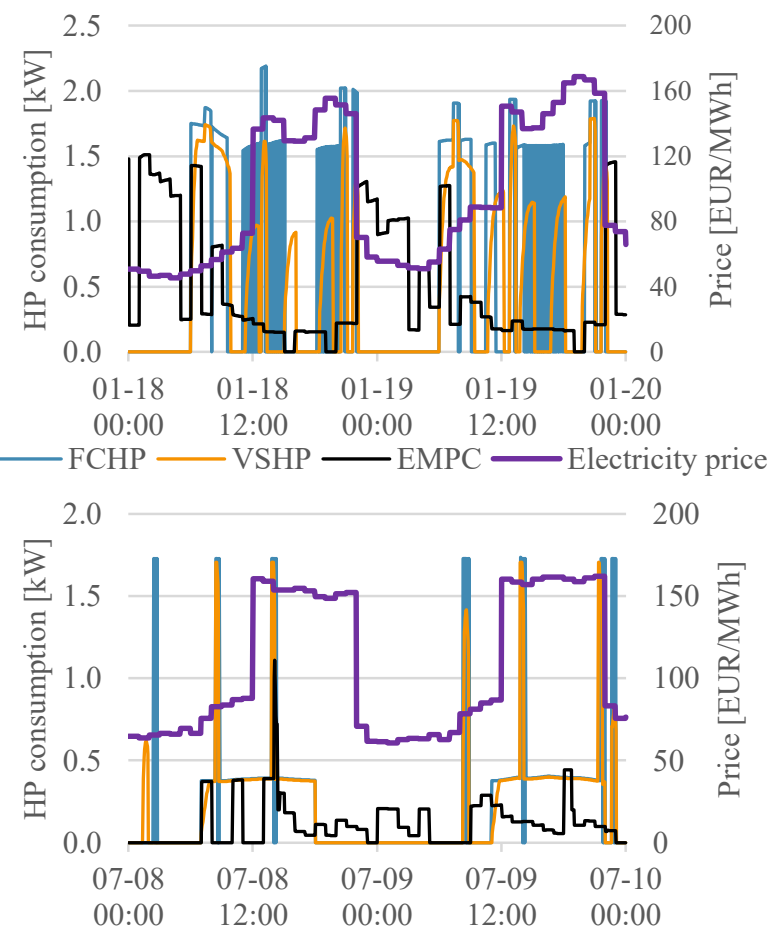

Figure 4: HP power consumption in winter (top) and summer (bottom) similar in both seasons, so the building is more cooled in the night, when it is colder outside, but in the summer case it is beneficial thanks to lower cooling losses.

Furthermore, the level of thermal comfort of the occupants is highest with the thermal-driven control of the building, while it is slightly reduced when flexibility is activated as can be seen for the LPD in Figure 5 . However, the indicator for all the scenarios is within the range of $5.5 \%$ and $8.0 \%$, well below the discomfort limit of $20.0 \%$. Therefore, thermal comfort is not jeopardized by the introduction of the EMPC strategy.

An interesting finding is that, even if it is not explicitly the objective of the EMPC strategy, peak shaving is achieved. This result is due to the use of the heat pump at low PLR, even lower than Scenario VSHP that already uses the HP at part load. In fact, the percentage of time when the HP has an electrical consumption higher than $60 \%$ of the HP rated input power decreases by $76.77 \%$ in winter and by $98.63 \%$ in summer in the energy flexibility strategies compared to Scenario VSHP. As a consequence, the HP is activated during longer periods.

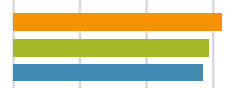

$$
\begin{aligned}
& \begin{array}{lllllllllll}
0 \% & 2 \% & 4 \% & 6 \% & 8 \% & 10 \% & 12 \% & 14 \% & 16 \% & 18 \% & 20 \%
\end{array} \\
& \text { 口EMPC } \square \text { VSHP } \square \text { FCHP }
\end{aligned}
$$

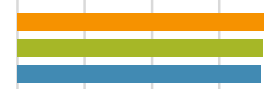

$\begin{array}{lllllllllll}0 \% & 2 \% & 4 \% & 6 \% & 8 \% & 10 \% & 12 \% & 14 \% & 16 \% & 18 \% & 20 \%\end{array}$ Long-term percentage of dissatisfied (LPD)

Figure 5: LPD of winter (top) and summer (bottom) simulations

\section{Conclusion}

The aim of the present research was to present the design and implementation of a VSHP in TRNSYS and to examine its behaviour in an energy flexibility scenario of MPC. Using the developed models, the VSHP proved to be more efficient than the FCHP, achieving an electricity consumption reduction of $16.10 \%$ in winter and of $6.23 \%$ in summer, due to its ability to work at part load where the HP efficiency is higher. Moreover, the EMPC strategy achieved its objective by reducing the electricity cost by approximately $50 \%$ in both seasons, successfully achieving load shifting towards low-price hours. However, the level of thermal comfort of the occupants was slightly reduced when flexibility was activated yet remains far from discomfort levels. In conclusion, the developed model of a VSHP achieved interesting results both when applied in conventional control strategy and EMPC, while MPC showed to be a promising technique that is able to provide energy flexibility in buildings equipped with heat pumps. Future work should focus on the experimental validation of the part load curve of the developed VSHP model, on the analysis of different MPC strategies to further examine the flexibility potential of a VSHP, and on the assessment and estimation of the uncertainties. 


\section{Acknowledgement}

This work has received funding from the European Union's Horizon 2020 research and innovation programme under the Marie Skłodowska-Curie grant agreement No 675318 (INCITE).

\section{References}

Bacher, P., \& Madsen, H. (2011). Identifying suitable models for the heat dynamics of buildings. Energy and Buildings, 43, 1511-1522.

Burba, M. (2013). Improved energy efficiency of air cooled chillers. REHVA, 50-53.

European Commission. (2016). Proposal for a Directive of the European Parliament and of the Council amending Directive 2010/31/EU on the energy performance of buildings 2016/0381 (COD). 0381.

European Commission. (2018). EU Buildings Database. Retrieved May 8, 2018, from European Commission Energy website: https://ec.europa.eu/energy/en/eubuildings-database

European Committee for Standardization (CEN). (2013). EN 14825-2013: Air conditioners, liquid chilling packages and heat pumps, with electrically driven compressors, for space heating and cooling -Testing and rating at part load conditions and calculation of seasonal performance. Brussels, Belgium.

European Heat Pump Association (EHPA). (2018). EHPA Stats. Retrieved July 3, 2018, from http://stats.ehpa.org/hp_sales/story_sales/

Fahlén, P. (2012). Capacity control of heat pumps. REHVA, 28-31.

Filliard, B., Guiavarch, A., \& Peuportier, B. (2009). Performance evaluation of an air-to-air heat pump coupled with temperate air-sources integrated into a dwelling. 11th Conference of International Building Performance Simulation Association, 2266-2273. Glasgow, Scotland.

Fuentes, E., Waddicor, D., Fannan, M. O., \& Salom, J. (2017). Improved methodology for testing the part load performance of water-to-water heat pumps. $12 \mathrm{th}$ IEA Heat Pump Conference 2017.

Gurobi Optimization LLC. (2018). Gurobi Software. Retrieved from http://www.gurobi.com

Halvgaard, R. (2014). Model Predictive Control for Smart Energy Systems (Technical University of Denmark (DTU)). Technical University of Denmark (DTU).

Hitachi Air Conditioning Products Europe. (2016). Technical Catalogue - Yutaki Series (pp. 1-256). pp. 1-256. Hitachi Air Conditioning Products Europe.

Horikawa, S., Tanaka, H., \& Sugihara, K. (2018). Daikin Technology and Innovation Center, Osaka, Japan. Retrieved September 15, 2018, from High Performing Buildings Magazine website: http://www.hpbmagazine.org/Daikin-Technologyand-Innovation-Center-Osaka-Japan/
Jensen, S. Ø., Marszal-Pomianowska, A., Lollini, R., Pasut, W., Knotzer, A., Engelmann, P., ... Reynders, G. (2017). IEA EBC Annex 67 Energy Flexible Buildings. Energy and Buildings, 155, 25-34.

Le Dréau, J., \& Heiselberg, P. (2016). Energy flexibility of residential buildings using short term heat storage in the thermal mass. Energy, 111, 991-1002.

Lofberg, J. (2004). YALMIP : a toolbox for modeling and optimization in MATLAB. 2004 IEEE International Conference on Robotics and Automation (IEEE Cat. No.04CH37508), 284-289.

Maasoumy, M., Razmara, M., Shahbakhti, M., \& Vincentelli, A. S. (2014). Handling model uncertainty in model predictive control for energy efficient buildings. Energy and Buildings, 77, 377-392.

Ortiz, J. (2016). Detailed energy and comfort simulation of integral refurbishment of existing buildings in Catalonia (Universitat Politècnica de Catalunya). Universitat Politècnica de Catalunya.

Péan, T. Q., Salom, J., \& Costa-Castelló, R. (2018a). Configurations of model predictive control to exploit energy flexibility in building thermal loads. 57th IEEE Conference on Decision and Control. Miami Beach, FL, USA.

Péan, T. Q., Salom, J., \& Costa-Castelló, R. (2018b). Review of control strategies for improving the energy flexibility provided by heat pump systems in buildings. Journal of Process Control.

Red Eléctrica de España. (2017). Término de facturación de energía activa del PVPC. Retrieved May 8, 2018, from Red Eléctrica de España website: https://www.esios.ree.es/es/pvpc

Reynders, G., Diriken, J., \& Saelens, D. (2014). Quality of grey-box models and identified parameters as function of the accuracy of input and observation signals. Energy and Buildings, 82, 263-274.

Schibuola, L., Scarpa, M., \& Tambani, C. (2015). Demand response management by means of heat pumps controlled via real time pricing. Energy and Buildings, 90, 15-28.

Siegenthaler, J. (2016). John Siegenthaler Investigates: Low Ambient Air-to-Water Heat Pumps: Low Ambient Air-to-Water Heat Pumps. Retrieved November 27, 2018, from HeatSpring Magazine website: https://blog.heatspring.com/low-ambientair-water-heat-pumps/

Swedish Energy Agency. (2018). Luftvattenvärmepumpar. Retrieved July 19, 2018, from http://www.energimyndigheten.se/tester/testera-o/luftvattenvarmepumpar/

Verhelst, C. (2012). Model Predictive Control of Ground Coupled Heat Pump Systems for Office Buildings. Katholieke Universiteit Leuven. 